\title{
EFECTO DEL DILUTOR TRIS Y CITRATO CON YEMA DE HUEVO DE CORDORNIZ SOBRE LA VIABILIDAD ESPERMÁTICA EN SEMEN OVINO CONGELADO EN PAJILLAS
}

\section{Effect of Tris and Citrate - Quail Egg Yolk Extenders on Viability of Ovine Frozen SEMEN in STraws}

\author{
Próspero Cabrera V. ${ }^{1}$, Arturo Ayulo L. ${ }^{1,2}$, César Pantoja A. ${ }^{3}$
}

\section{Resumen}

Se evaluó el comportamiento de los dilutores Tris-yema y Citrato-yema en el congelamiento de semen de ovino y la integridad de la membrana espermática del semen congelado en pajillas. El estudio se realizó en el Banco Nacional de Semen UNALM con seis carneros de tres razas. El semen se colectó en vagina artificial, se diluyó con Tris glucosa - yema de huevo de Codorniz (Tris) o Citrato - glucosa - yema de huevo (Citrato), se almacenó en pajillas de $0.5 \mathrm{ml}$, y se congeló en nitrógeno líquido. El descongelamiento se realizó a $38^{\circ} \mathrm{C}$ por 15 segundos. En semen refrigerado, la Motilidad Individual Progresiva (MIP) en semen diluido con Tris fue $82.3 \%$ y con Citrato de $79.2 \%$, y los valores de la integridad de membrana (HOST) fueron de $78.0 \pm 4.4$ con Tris y $73.2 \pm 5.8 \%$ con Citrato. En semen descongelado, la MIP fue de 62.0 y $56.8 \%$, y HOST de $49.8 \pm 3.9$ y $41.3 \pm 3.8 \%$ para los dilutores Tris y Citrato, respectivamente, existiendo diferencias significativas entre dilutores, carneros y momentos de procesamiento $(\mathrm{p}<0.01)$. Se registraron regresiones lineales significativas ( $\mathrm{p}<0.001$ ) entre MIP del semen refrigerado y HOST de semen descongelado con uso de ambos dilutores. Se concluye que Tris presenta un mejor rendimiento que Citrato para la congelación del semen ovino y que la prueba hipoosmótica permitió evidenciar diferencias entre dilutores, carneros y momentos de procesamiento.

Palabras clave: dilutores, semen congelado, ovinos, pajillas

\section{Abstract}

The study evaluated the performance of Tris-egg yolk and Citrate-egg-yolk as extenders for freezing ram semen in straws and the integrity of sperm membrane of frozen sperm at the National Semen Bank - UNALM, Lima, Peru using six ram semen donors of three breeds. The semen was collected in an artificial vagina, diluted with Tris - glucose - quail egg yolk (Tris) or with Citrate - glucose - egg yolk (Citrate), stored in $0.5 \mathrm{ml}$ pellets, and frozen in liquid nitrogen. Thawing was done at $38{ }^{\circ} \mathrm{C}$ for 15 seconds. In refrigerated semen, the Progressive Individual Motility (PIM) in diluted semen with Tris

\footnotetext{
${ }^{1}$ Departamento de Producción Animal, Facultad de Zootecnia, Universidad Nacional Agraria La Molina (UNALM), Lima

${ }^{2}$ E-mail: arturoayulo@hotmail.com

${ }^{3}$ Escuela de Zootecnia, Universidad Nacional Daniel Alcides Carrión, Cerro de Pasco
} 
was $82.3 \%$ and with Citrate was $79.2 \%$, and the integrity of the cytoplasmic membrane (HOST) was $78.0 \pm 4.4$ with Tris and $73.2 \pm 5.8 \%$ with Citrate. In thawed semen, PIM was 62.0 and $56.8 \%$, and HOST was $49.8 \pm 3.9$ and $41.3 \pm 3.8 \%$ for Tris and Citrate respectively, with significant differences between extenders, rams and processing period $(\mathrm{p}<0.01)$. There were significant lineal regressions $(\mathrm{p}<0.001)$ between PIM of refrigerated semen and HOST after thawing for both extenders. It was concluded that Tris showed better performance than Citrate for freezing ram semen, and the hipoosmotic swelling test allowed to show differences between extenders, rams and processing periods.

Key words: extenders, frozen semen, sheep, semen straws

\section{INTRODUCCIÓN}

La inseminación artificial en el ovino ha despertado el interés de los ganaderos, con el fin de mejorar los sistemas de explotación y la calidad genética del rebaño. Las ventajas de la inseminación artificial se incrementan con la disponibilidad de carneros de alto valor genético y con la posibilidad de congelar el semen para permitir un uso más racional. Esto último permite magnificar el uso de los sementales, disminuir los costos de producción y poder adquirir machos de calidad genética comprobada.

El semen obtenido del carnero con motilidad superior a $85 \%$ y menos de $10 \%$ de espermatozoides anormales se considera de alta calidad (Pérez y Pérez, 1999). La congelación del esperma del macho ovino plantea el uso de semen de alta calidad durante todo el proceso a fin de alcanzar mejores resultados, es decir, el mayor número posible de espermatozoides móviles y fecundantes después de la descongelación.

Los diluyentes de semen deben contener agentes protectores para las membranas celulares durante el enfriamiento a $5{ }^{\circ} \mathrm{C}$ (generalmente yema de huevo) y el congelamiento (generalmente glicerol) para evitar lesiones de la membrana (Hafez, 1996). La adición de yema de huevo al dilutor tiene un efecto benéfico sobre el porcentaje de motilidad, particularmente después de un rápi- do enfriamiento del semen. Las lipoproteínas de baja intensidad actúan como crioprotectores (Watson, 1981), ya que protegen contra el shock de frío (factor de resistencia) y mantienen la viabilidad (factor de conservación) (Fiser y Fairfull, 1986).

El semen de ovino presenta una aceptable supervivencia espermática al proceso de congelación, lográndose una fertilidad de 25 y $45 \%$ en ovejas inseminadas (García et al., 1992). Estas tasas de fertilidad podrían ser mejoradas si se pone especial énfasis en la composición de los dilutores y su efecto sobre la integridad de la membrana citoplasmática del espermatozoide. En condiciones fisiológicas normales, la fecundación no ocurre si la membrana plasmática del espermatozoide está bioquímicamente inactiva, aun cuando permanezca estructuralmente intacta; por lo tanto, la prueba hipoosmótica es un buen indicador del funcionamiento de la membrana espermática (Tamuli y Watson, 1992). Esta prueba muestra una correlación positiva moderada con la fertilidad (0.536) a diferencia de la motilidad que presenta una correlación nula (0.032) con la capacidad fecundante del macho (Pantoja, 2007). En base a esto, el motivo del presente trabajo fue evaluar el comportamiento de los dilutores Tris y citrato con yema de huevo de codorniz sobre la motilidad del semen durante el congelamiento en pajillas, así como la calidad del semen congelado a través de la prueba hipoosmótica. 


\section{Materiales y Métodos}

\section{Lugar de Ejecución y Animales}

El estudio se realizó en las instalaciones del Banco Nacional de Semen de la Universidad Nacional Agraria la Molina, Lima. Se utilizaron seis carneros (2 Blackbelly, 2 Canelas y 2 Assaf) de 3.5 años. Los animales pertenecían a la universidad y al Instituto Nacional de Innovación Agraria (INIA), y fueron manejados en confinamiento bajo un mismo régimen de alimentación y cuidados sanitarios. Los animales permanecieron en las instalaciones del Banco de Semen por 20 semanas (8 para la fase pre-experimental [adiestramiento] y 12 para la fase experimental).

Se dispuso de un corral de $5 \mathrm{~m}^{2}$ para cada dos carneros y un corral aislado para una hembra que se empleó para la colección se semen en el brete de monta. Los corrales contaban con arpilleras que daban sombra al $80 \%$ del área. La alimentación se basó en forraje verde picado de King grass (Pennisetum purpureum $\mathrm{x}$ Pennisetum typhoides), maíz chala (Zea mays) picado y un suplemento concentrado (14\% de proteína, $17.5 \%$ de fibra, y $68.5 \%$ de NDT) para cubrir los requerimientos nutricionales de los animales. El reparto del forraje fue dos veces por día, y el concentrado se proporcionó en las mañanas. El agua se dispuso ad-libitum.

\section{Colección y Evaluación de Semen}

La colección de semen se hizo dos veces por semana en un brete de colección de $1.0 \times 0.80 \times 1.20 \mathrm{~m}$, con una fosa de $1.75 \mathrm{~m}$ de largo, $0.74 \mathrm{~m}$ de ancho y $1.02 \mathrm{~m}$ de profundidad. El brete contaba con sombra, y la colección se hizo con apoyo de una hembra.

El semen se colectó empleando una vagina artificial (IMV®) para ovinos, termorregulada con agua a $35{ }^{\circ} \mathrm{C}$. Las 60 muestras se semen utilizadas en el presente estudio se tomaron al azar de un total de 100 eyaculados colectados en un periodo de 12 semanas. El volumen del eyaculado se deter- minó por observación directa en tubo colector graduado. Se consideró que un semen de color blanco cremoso y de motilidad masal grado 5 era de una excelente calidad, y podía ser destinado a congelación. Además, se determinó el aspecto (grado de opacidad, variando de denso cremoso hasta denso acuoso) y el $\mathrm{pH}$ con una cinta colorimétrica.

En la evaluación microscópica se consideró:

a) Motilidad, expresada en porcentaje, a través de la observación del movimiento individual del espermatozoide en láminas portaobjetos, mediante microscopio a 20 y $40 \mathrm{X}$, sobre platina temperada a $37{ }^{\circ} \mathrm{C}$.

b) Concentración espermática, mediante el hemocitómetro y la cámara de Neubauer para el conteo de espermatozoides (número de espermatozoides por mililitro).

c) Porcentaje de espermatozoides vivos y muertos, mediante la tinción con eosinanigrosina.

d) Morfología espermática, mediante tinción con tinta china. El porcentaje de células anormales se calculó en base al contaje de 100 células espermáticas.

e) Determinación de la integridad de membrana citoplasmática, mediante el test de endósmosis en solución hipoosmótica de citrato de sodio $(100 \mathrm{mOsm} / \mathrm{L})$, según Correa y Zavos (1994). Esta prueba mide la proporción de espermatozoides con membrana intacta luego de ser sometidos a un medio de baja osmolaridad. Los espermatozoides viables reaccionan mostrando un anillo en la cola. Los resultados se expresan en porcentaje.

Las evaluaciones de motilidad y endosmosis en el semen refrigerado se realizaron a las 6 y 24 horas con la finalidad de buscar el grado de relación entre la motilidad (evaluación subjetiva) vs la endosmosis (evaluación objetiva), y así poder determinar el momento adecuado que permita predecir la calidad del semen. 
Cuadro 1. Composición de los dilutores de semen ovino empleados en la investigación

\begin{tabular}{lcc}
\hline Componente & Dilutor Tris & Dilutor Citrato \\
\hline Tris $(\mathrm{g})$ & 3.634 & -- \\
Citrato sódico $(\mathrm{g})$ & -- & 2.37 \\
Glucosa $(\mathrm{g})$ & 0.5 & 0.8 \\
Ácido cítrico $(\mathrm{g})$ & 1.99 & -- \\
Yema de huevo de codorniz $(\mathrm{ml})$ & 15 & 20 \\
Glicerina (ml) & 5 & 5 \\
Penicilina (UI) & 100,000 & 100,000 \\
Estreptomicina (mg) & 100 & 100 \\
Agua destilada enrasar a (en $\mathrm{ml})$ & 100 & 100 \\
\hline
\end{tabular}

\section{Tratamientos Experimentales}

La composición de los dilutores Tris glucosa - yema de huevo de codorniz (Tris) y Citrato - glucosa - yema de huevo de codorniz (Citrato) se muestran en el Cuadro 1. El procedimiento de dilución se inició con la mezcla de los componentes químicos en un volumen apropiado de agua destilada, y luego se adicionó el glicerol y la yema de huevo.

\section{Dilución y Congelación}

Se tomó una alícuota de semen $(30 \mu \mathrm{l})$ para la evaluación inicial del eyaculado, e inmediatamente se procedió a una pre-dilución agregando el dilutor en la misma proporción del semen. Tanto el semen como el diluyente estaban en Baño María a $34{ }^{\circ} \mathrm{C}$. El dilutor fue preparado en el día de la colección de semen y temperado 15 minutos antes que el semen.

El número de pajillas a congelar se determinó en función de la concentración espermática del eyaculado. Se empleó $30 \mathrm{x}$ $10^{6}$ espermatozoides por dosis de semen (Cueto et al., 2003). El semen se envasó en pajillas Cassou IMV Technologies, Francia, de $0.5 \mathrm{ml}$, recomendado para el caso de ovinos (FAO, 1991).
Las pajillas se colocaron en cubetas con agua a temperatura de laboratorio $\left(25^{\circ} \mathrm{C}\right)$, y luego a refrigeración, descendiendo la temperatura desde $34^{\circ} \mathrm{C}$ a $5^{\circ} \mathrm{C}$ en dos horas. Quince minutos antes de cumplidas las dos horas, si la temperatura no estuviese a $5^{\circ} \mathrm{C}$, se agregó cubos de hielo a la cubeta, en forma gradual, hasta lograr la temperatura de $5^{\circ} \mathrm{C}$, en la parte final de la curva de enfriamiento y equilibrio.

Para la congelación de semen se siguió el protocolo descrito por Evans y Maxwell (1990) con las variantes basadas en los principios de congelación de células referido por Mazur et al. (1972). Se colocó las pajillas sobre una rejilla metálica, a $2 \mathrm{~cm}$ de la superficie $\left(5^{\circ} \mathrm{C}\right)$ del tanque de nitrógeno líquido, donde recibió los vapores de nitrógeno líquido durante 2 minutos $\left(-92^{\circ} \mathrm{C}\right)$, y luego fueron sumergidas $\left(-196^{\circ} \mathrm{C}\right)$ en el tanque.

\section{Descongelación y Evaluación}

El semen permaneció congelado por 15 días. La descongelación se hizo en un termo descongelador a $38{ }^{\circ} \mathrm{C}$, por espacio de 15 segundos. Se evaluó la motilidad individual progresiva, así como la integridad de membrana espermática con la técnica de HOST (hypoosmotic swelling test), según Correa y Zavos (1994). 


\section{Análisis Estadístico}

Se aplicó un test de normalidad para los datos numéricos. Los datos porcentuales se transformaron mediante arco seno con la fórmula $Y=\operatorname{arc} \operatorname{sen}\left[(x / 100)^{1 / 2}\right]$, donde " $x "$ representa el valor porcentual.

Para la evaluación de la respuesta a la motilidad e integridad de membrana espermática (endósmosis positiva), se empleó un diseño de bloques completamente al azar, con arreglo factorial $2 \times 2 \times 6$, con error de muestreo, siendo los factores a evaluar dos diluyentes de semen (Tris y Citrato), en dos momentos del procesamiento (refrigerado y congelado). Se consideró como bloques cada uno de los carneros $(n=6)$. El modelo aditivo lineal usado fue el siguiente:

$$
\begin{aligned}
& \begin{aligned}
\mathrm{Y}_{\mathrm{ijk} 1}= & u+\mathrm{B}_{\mathrm{k}}+\mathrm{D}_{\mathrm{i}}+\mathrm{M}_{\mathrm{j}}+\left(\mathrm{D}^{*} \mathrm{M}\right)_{\mathrm{ij}}+\mathrm{e}_{\mathrm{ijk}} \\
& +1_{\mathrm{ijk} l}
\end{aligned} \\
& \text { donde } \\
& \mathrm{y}_{\mathrm{ijkl}}=\text { Variable respuesta de endósmosis }
\end{aligned}
$$

Se realizó un análisis de correlación entre las características (motilidad - host refrigerado y descongelado) en las que intervienen los dilutores. Además, se utilizó análisis de regresión lineal para determinar la dependencia entre las características seminales. En todos los análisis estadísticos se utilizó el programa SAS (Statistical Analysis System) para un error de 0.05, descrito por Pérez, (2001).

\section{Resultados y Discusión}

En el Cuadro 2 se muestran los resultados de la evaluación espermática de los eyaculados de los seis carneros, previos a la dilución y procesamiento para la congelación. Los promedios se encuentran dentro de los rangos esperados para la especie. No obstante, el volumen promedio del eyaculado fue superior a los volúmenes de 0.83 y $0.97 \mathrm{ml}$ obtenidos por Ramírez (2002) y Guillén (2001), respectivamente, con carneros Blackbelly, pero similar al reportado por Quispe et al. (1998), utilizando como método de colección la vagina artificial y una frecuencia de colección de dos veces al mes. La concentración espermática fue similar a otros reportes (Guillén, 2001; Ramírez, 2002).

La motilidad del semen refrigerado, previo a la congelación y conservado con dilutor Tris fue $82.3 \%$ y con Citrato de $79.2 \%$. La motilidad, luego de la descongelación fue de 62.0 y de $56.8 \%$ para los dilutores Tris y Citrato, respectivamente (Fig. 1). Se encontró diferencia estadística entre dilutores $(p<0.05)$ y entre carneros y momentos de procesamiento $(\mathrm{p}<0.01)$; sin embargo, no hubo diferencia por efecto de la interacción tiempo - dilutor. Ramírez (2002) encontró asimismo, una motilidad individual por encima del $70 \%$ hasta las 24 horas a $5{ }^{\circ} \mathrm{C}$.

La adición de yema de huevo al dilutor tiene un efecto benéfico sobre el porcentaje de motilidad, especialmente después de un rápido enfriamiento del semen a 10 y $5{ }^{\circ} \mathrm{C}$, ya que las lipoproteínas de baja intensidad actúan como crioprotectores, contribuyendo a la protección contra el shock de frío (factor de resistencia) y manteniendo la viabilidad del espermatozoide (factor de conservación) (Fiser y Fairfull, 1986). 
Cuadro 2. Características seminales (promedios \pm desviación estándar) de seis carneros con fines de congelación de semen

\begin{tabular}{lccccc}
\hline Carnero & $\begin{array}{c}\text { Volumen } \\
(\mathrm{ml})\end{array}$ & $\begin{array}{c}\text { Concentración } \\
\mathrm{x} 10^{6} / \mathrm{ml}\end{array}$ & $\begin{array}{c}\text { Espermatozoides } \\
\text { vivos }(\%)\end{array}$ & $\begin{array}{c}\text { Anormalidades } \\
(\%)\end{array}$ & $\begin{array}{c}\text { Integridad } \\
\text { de } \\
\text { membrana } \\
(\%)\end{array}$ \\
\hline BB-INIA & $1.2 \pm 0.2$ & 3983 & $87.4 \pm 1.1$ & $5.3 \pm 1.3$ & $80.5 \pm 4.7$ \\
BB-UNA & $1.2 \pm 0.3$ & 2428 & $83.8 \pm 5.1$ & $6.6 \pm 1.4$ & $83.4 \pm 3.2$ \\
Canela C & $1.1 \pm 0.4$ & 2570 & $80.8 \pm 7.4$ & $5.1 \pm 1.6$ & $82.9 \pm 7.8$ \\
Canela O & $1.1 \pm 0.5$ & 3021 & $84.5 \pm 6.0$ & $7.4 \pm 2.2$ & $81.5 \pm 5.2$ \\
Assaf C & $2.3 \pm 0.7$ & 2189 & $85.6 \pm 3.5$ & $6.9 \pm 1.0$ & $84.3 \pm 3.4$ \\
Assaf M & $1.6 \pm 0.5$ & 3274 & $87.0 \pm 4.1$ & $8.5 \pm 2.4$ & $84.9 \pm 4.3$ \\
\hline Promedio & $1.4 \pm 0.4$ & 2911 & $84.8 \pm 4.5$ & $6.6 \pm 1.6$ & $83.0 \pm 4.7$ \\
\hline
\end{tabular}

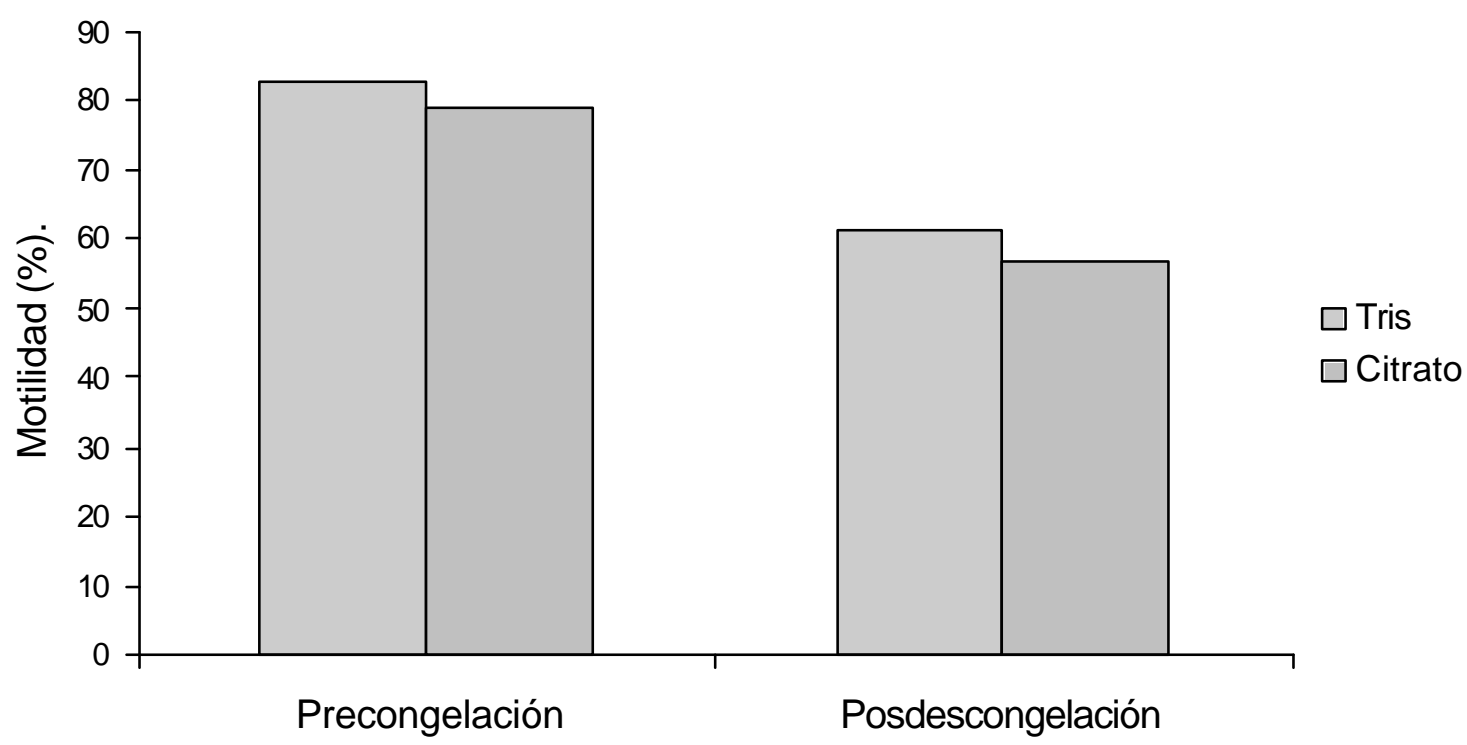

Figura 1. Porcentaje de motilidad en semen refrigerado y en semen descongelado de ovinos, utilizando dos dilutores

La membrana espermática en el semen refrigerado, momentos antes del proceso de congelamiento, estuvo intacta en el $78.0 \pm$ 4.4 y $73.2 \pm 5.9 \%$ de los espermatozoides, en los casos donde se usó el dilutor Tris y Citrato, respectivamente. Los valores de endósmosis obtenidos para cada carnero, en semen re- frigerado usando Tris fueron de $67.5 \pm 1.41$, $77.9 \pm 3.1,77.4 \pm 8.2,80.0 \pm 5.1,82.5 \pm 4.0 \mathrm{y}$ $82.9 \pm 4.9$, y para el Citrato de $59.4 \pm 6.5$, $74.4 \pm 1.4,66.8 \pm 8.1,75.8 \pm 9.7,82.4 \pm 4.0 \mathrm{y}$ $80.6 \pm 5.2 \%$. Estos resultados indican que el dilutor Tris conserva mejor el semen en estado refrigerado. La diferencia en los valores 
Cuadro 3. Motilidad y endósmosis en tres grupos raciales de carneros y empleando dos dilutores para el congelamiento de semen

\begin{tabular}{llcccc}
\hline \multirow{2}{*}{$\begin{array}{l}\text { Raza del } \\
\text { carnero }\end{array}$} & Momento & \multicolumn{2}{c}{ Motilidad } & \multicolumn{2}{c}{ Endosmosis } \\
\cline { 3 - 6 } & & Tris & Citrato & Tris & Citrato \\
\hline \multirow{2}{*}{ B B } & Refrigerado & $83.1 \pm 3.5$ & $81.9 \pm 2.6$ & $72.7 \pm 5.9$ & $66.9 \pm 9.0$ \\
& Post descongelado & $63.7 \pm 2.7$ & $58.1 \pm 5.1$ & $52.1 \pm 3.2$ & $41.0 \pm 3.0$ \\
\multirow{2}{*}{ Asaf } & Refrigerado & $84.3 \pm 3.8$ & $79.3 \pm 8.7$ & $82.7 \pm 4.3$ & $81.5 \pm 4.5$ \\
& Post descongelado & $61.7 \pm 6.5$ & $55.7 \pm 8.5$ & $49.0 \pm 3.3$ & $42.5 \pm 5.8$ \\
\multirow{2}{*}{ Canela } & Refrigerado & $79.5 \pm 5.6$ & $76.4 \pm 5.5$ & $78.7 \pm 6.7$ & $71.3 \pm 9.8$ \\
& Post descongelado & $60.5 \pm 6.4$ & $56.8 \pm 6.1$ & $48.3 \pm 5.3$ & $40.3 \pm 4.6$ \\
\hline
\end{tabular}

Cuadro 4. Regresiones y correlaciones entre motilidad y endosmosis en diferentes momentos del proceso de congelación de semen de carnero y con el uso de dos dilutores

\begin{tabular}{lccc}
\hline Parámetros relacionados & Regresión & Correlación & Significancia \\
\hline $\begin{array}{l}\text { Endosmosis Tris 6 h de refrigerado - } \\
\text { Endosmosis Tris 24 h de refrigerado }\end{array}$ & 0.5648 & 0.8786 & $\mathrm{p}<0.001$ \\
$\begin{array}{l}\text { Motilidad Tris 24 h de refrigerado - } \\
\text { Motilidad Tris descongelado }\end{array}$ & 0.3752 & 0.7748 & $\mathrm{p}<0.001$ \\
$\begin{array}{l}\text { Motilidad Tris 24 h de refrigerado - } \\
\text { Endosmosis Tris descongelado }\end{array}$ & & 0.0001 \\
$\begin{array}{l}\text { Motilidad Tris descongelado - } \\
\text { Endosmosis Tris descongelado }\end{array}$ & & 0.8850 & $\mathrm{p}<0.001$ \\
$\begin{array}{l}\text { Endosmosis Citrato 6 h de refrigerado - } \\
\text { Endosmosis Citrato 24 h de refrigerado }\end{array}$ & & & \\
$\begin{array}{l}\text { Motilidad Citrato 24 h de refrigerado - } \\
\text { Motilidad Citrato descongelado }\end{array}$ & 0.6017 & 0.0018 & $\mathrm{p}<0.001$ \\
$\begin{array}{l}\text { Motilidad Citrato 24 h de refrigerado - } \\
\text { Endosmosis Citrato descongelado }\end{array}$ & 0.3112 & 0.6875 & $\mathrm{p}<0.001$ \\
$\begin{array}{l}\text { Motilidad Citrato descongelado - } \\
\text { Endosmosis Citrato descongelado }\end{array}$ & & 0.7109 & $\mathrm{p}<0.001$ \\
\hline
\end{tabular}

de integridad de membrana de ambos dilutores estaría probablemente influenciada por la proporción de ácido cítrico - citrato de sodio que contiene los dilutores, debido a que este elemento ejerce acción directa sobre la fijación de calcio en la membrana de los espermatozoides, que junto con los iones de sodio y potasio, mantienen el equilibrio osmótico favoreciendo la motilidad de los espermatozoides (Borque y Saguez, 1992). 
La membrana espermática, posterior al proceso de congelación fue de $49.8 \pm 3.9$ para el dilutor Tris y de $41.3 \pm 3.8 \%$ para Citrato. Se encontró diferencia estadística $(\mathrm{p}<0.01)$ entre dilutores, entre carneros y entre momentos de procesamiento. La interacción tiempo - dilutor, al igual que con la motilidad, no mostró diferencias significativas.

En el Cuadro 3 se observa el comportamiento de la motilidad del semen durante los momentos de procesamiento para cada grupo racial. La motilidad post congelamiento se vio disminuida entre 19 a $23 \%$ en el caso del dilutor Tris y de 20 a $24 \%$ para el dilutor Citrato. Esta reducción fue menor a lo reportado por Thomas et al. (1998) quienes afirman que durante el proceso de criopreservación se produce una disminución del $50 \%$ en la viabilidad espermática, debido principalmente al efecto de la temperatura y la presión osmótica, ocurriendo cambios en la organización morfológica de las células, tales como la permeabilidad, composición lipídica de las membranas espermáticas y en el líquido intracelular.

En el Cuadro 4 se muestran las regresiones y correlaciones entre la motilidad y la endosmosis en diferentes momentos del proceso de congelación del semen. La regresión y correlación mas importante se da entre la motilidad del semen a las $24 \mathrm{~h}$ de refrigerado con la endósmosis del semen descongelado, situación que se observa en ambos dilutores $(\mathrm{p}<0.001)$; lo cual indica la posibilidad de predecir la calidad del semen antes de congelamiento, permitiendo de ese modo, optimizar el rendimiento de los sementales y la mano de obra.

\section{Conclusiones}

? Es factible la congelación de semen de ovinos en pajillas de $0.5 \mathrm{ml}$.

? El dilutor Tris - yema de huevo de codorniz preserva mejor a los espermatozoides durante el proceso de congelación, respecto al dilutor citrato yema de huevo de codorniz.
? La prueba hipoosmótica permitió evidenciar diferencias entre dilutores, entre carneros y momentos de procesamiento.

? El valor de la motilidad permite predecir la calidad de la integridad de membrana en los espermatozoides.

\section{Literatura Citada}

1. Borque M, Saguez A. 1992. Variaciones estacionales de los niveles de fructosa, ácido cítrico y proteínas totales en eyaculados de moruecos de raza Manchega. Invest Agr Prod Sanid Anim 7(3): 235-240.

2. Correa JR, Zavos PM. 1994. The hipoosmotic swelling test: Its employment as an assay to evaluate the functional integrity of the frozen-thawed sperm characteristics assessed via the routine semen analysis, sperm functional test and fertility of bullsin an artificial insemination program. Theriogenology 48: 721-731.

3. Cueto M, Garcia J, Arrigo J, Gibbons

A. 2003. Obtención, procesamiento y conservación del semen ovino. Comunicación Técnica PA 200. Bariloche, Argentina: INTA.14 p.

4. Evans G, Maxwell W. 1990. Salamon's artificial insemination of sheep and goats. London: Ed Butterworth. 122 p.

5. FAO. 1991. Training manual on artificial insemination in sheep and goats. FAO Animal Production and Health Paper $N^{\circ}$ 83. Rome: FAO. 222 p.

6. Fiser PS, Fairfull RW. 1986. The effect of rapid cooling (cold shock) of ram semen, photoperiod, and egg yolk in diluyents on the survival of spermatozoa before and after freezing. Criobiology 23: 518-524.

7. García García RM, Domínguez V, Gonzales Bulnes A, Veiga López A, Cocero MJ. 1992. Efecto de la concentración de sacarosa sobre la supervivencia post-descongelación de embriones ovinos en distintos estadios del desarrolo preimplantacional. ITEA 24: 229-281. 
8. Guillén H. 2001. Evaluación de las características seminales en carneros Blackbelly. Tesis de Ing. Zootecnista. Lima: Universidad Nacional Agraria La Molina. $68 \mathrm{p}$.

9. Hafez ESE. 1996. Reproducción e inseminación artificial en animales. $6^{a}$ ed. México: Interamericana McGraw-Hill. $694 \mathrm{p}$.

10. Mazur P, Leibo SP, Chu E. 1972. A two factor hypothesis of freezing injury. Evidence from Chinese hamster tissue culture cells. Expl Cell Res 71: 345-355.

11. Pantoja AC. 2007. Evaluación de dos dilutores en semen congelado y su efecto en la fertilidad de ovejas, inseminadas por vía laparoscópica en sierra central. Tesis de Maestría. Lima: Univ Nacional Agraria La Molina. 110 p.

12. Pérez y Pérez F. 1999. Reproducción animal: inseminación artificial y transplante de embriones. Barcelona: Ed Científico Médica. $420 \mathrm{p}$.

13. Pérez López C. 2001. El sistema estadístico SAS. España: Instituto Complutense de Madrid. $320 \mathrm{p}$.

14. Quispe F, Cárdenas H, Gutiérrez G, Flores E. 1998. Algunas característi- cas físicas del semen en 4 razas de carneros. XXI Reunión Científica Anual APPA. UNA Puno: Asociación Peruana de Producción Animal.

15. Ramírez CA. 2002. Efecto de tres dilutores y tres tiempos de refrigeración en la motilidad individual del semen refrigerado de carneros Black Belly. Tesis de Ing. Zootecnista. Lima: Universidad Nacional Agraria La Molina. 93 p.

16. Tamuli MK, Watson PF. 1992. Effects of temperature of incubation on the development of resistance to cold stress in boar spermatozoa incubated for up 24 hours. Proc $12^{\text {th }}$ ICAR Congress. The Hague: ICAR. p 1484-1486.

17. Thomas CA, Garner DL, Dejarnette JM, Marshall CE. 1998. Effect of cryopreservation on bovine sperm oganelle function and viability as determined by flow cytometry. Biol Reprod 58: 786-793.

18. Watson PF. 1981. The roles of lipid and protein in the protection of ram spermatozoa at $5{ }^{\circ} \mathrm{C}$ by egg yolk lipoprotein. J Reprod Sci 37: 156-157. 